\title{
Establishment of a mouse model of lipopolysaccharide-induced neutrophilic nasal polyps
}

\author{
SHUIBIN WANG ${ }^{1}$, HANWU ZHANG $^{1}$, ZULIAN XI $^{1}$, JINGJING HUANG $^{1}$, \\ JUN NIE ${ }^{1}$, BIN ZHOU $^{1}$, YUQIN DENG ${ }^{2}$ and ZEZHANG TAO ${ }^{2}$ \\ ${ }^{1}$ Department of Otolaryngology-Head and Neck Surgery, Yichang Yiling Hospital, Yichang, Hubei 443100; ${ }^{2}$ Department \\ of Otolaryngology-Head and Neck Surgery, Renmin Hospital of Wuhan University, Wuhan, Hubei 430060, P.R. China
}

Received January 1, 2016; Accepted February 10, 2017

DOI: $10.3892 / \mathrm{etm} .2017 .5208$

\begin{abstract}
Research has identified that gram-negative bacteria have an important role in refractory nasal polyps. In the present study, lipopolysaccharide (LPS) was used to establish a mouse model with neutrophilic nasal polyps in order to explore the effect and mechanism of LPS on the formation of neutrophilic nasal polyps in mice. A total of 5 or $10 \mu \mathrm{g}$ of LPS was dropped into the nasal cavities of C57BL/6 J mice in order to establish animal models with neutrophilic nasal polyps. Histological staining, toll-like receptor 4 (TLR4), cluster of differentiation 68 for macrophages and myeloperoxidase for neutrophil immunohistochemistry were used to observe histopathological changes in the nasal mucosa. The expression levels of cytokines, including interferon (IFN)- $\gamma$, tumor necrosis factor (TNF)- $\alpha$, interleukin (IL)- 4 and IL-17 in the nasal lavage fluid, were detected by ELISA. Compared with the control group, mice in the LPS groups exhibited significant mucosa epithelial cell damage and nasal polyp formation. Furthermore, TLR4 ${ }^{+}$cells, macrophages, neutrophils and significantly increased levels of IFN- $\gamma$, TNF- $\alpha$, and IL-17 in the nasal lavage fluids were indicated (all $\mathrm{P}=0.008$ ). These findings indicated that LPS is able to activate the TLR4 receptor pathway to induce the formation of neutrophilic nasal polyps in mice. Additionally, LPS administration was accompanied by a significant increase in the number of macrophages, $\mathrm{T}$ helper (Th) 1 and Th17-related cytokines $(\mathrm{P}=0.009, \mathrm{P}=0.008$ and $\mathrm{P}=0.008$, respectively). Therefore, the present model is commensurate with the characteristics of primary nasal polyps that have been identified in the Asian population.
\end{abstract}

Correspondence to: Professor Zezhang Tao, Department of Otolaryngology-Head and Neck Surgery, Renmin Hospital of Wuhan University, 238 Jiefang Road, Wuhan, Hubei 430060, P.R. China E-mail: zezhangtaoent@163.com

Key words: chronic rhinosinusitis, lipopolysaccharide, nasal polyps, neutrophils

\section{Introduction}

Nasal polyps, a common and frequently-occurring disease in the upper respiratory tract, have a negative effect on patient quality of life and are considered a heavy economic burden for patients, their families and society in general $(1,2)$. Nasal polyps are divided into two types, according to the inflammatory cells affected. One type consists primarily of eosinophils while the other consists primarily of neutrophils $(1,2)$. Each type is associated with different immune histopathologic features. Patients with the former type are predominantly encountered in Europe and the United States and other Western countries, while patients with the latter type are typically encountered in Asia $(1,3)$. The cause of nasal polyps is not entirely clear; however, multiple factors, such as viruses, bacteria, fungi and allergens have been implicated (1-3). Although the use of intranasal corticosteroids and functional endoscopic sinus surgery may significantly improve the cure rate of nasal polyps, $\sim 10 \%$ of patients will continue to experience recurrent nasal polyps post-surgery (4). Therefore, the internal mechanisms of nasal polyp formation require further elucidation.

In vivo studies of human diseases are often limited in clinical settings due to ethical considerations and other issues pertaining to patient safety; therefore, disease-related animal models have been developed as a more effective means of conducting such in vivo studies. Mice are the typical laboratory animals used in disease models due to their extensive availability, affordability and the closely related genetic complements of mice and humans (5). Although several studies have been conducted using mouse models of chronic rhinosinusitis (6-8), few studies have used mouse models of nasal polyps. This paucity of research has not been conducive to the study of the pathophysiology of nasal polyps and has stunted the formulation of strategies for the prevention of the disease. Kim et al $(5,9)$ successfully established the first mouse model of eosinophilic nasal polyps using ovalbumin combined with staphylococcal enterotoxin. However, to date, mouse models of neutrophilic nasal polyps have not been reported domestically or internationally.

The bacterial endotoxin is a unique cell wall structure of Gram-negative bacilli and is an exogenous pyrogen. Thus, bacterial endotoxins are able to activate neutrophils to release various types of endogenous pyrogen, which affect the thermoregulatory 
center to cause fever (10). Lipopolysaccharides (LPS), one of the principal chemical components of the bacterial endotoxin, are located in the outer layer of the Gram-negative bacterial cell wall and consist of three parts: Lipid A, core polysaccharide and O-specific polysaccharide. In addition to its toxic effects, LPS is able to induce an immune response $(6,10)$. Although neutrophilic nasal polyps have been associated with a variety of bacterial infections, refractory nasal polyps have been revealed to be closely associated with Gram-negative bacteria infection and the endotoxins and LPS released by Gram-negative bacteria are considered to be important pathogenic mechanisms $(11,12)$. While endotoxin may be a noninfectious inflammatory factor, it is able to regulate the release of inflammatory mediators, resulting in chronic rhinosinusitis (10). Kim et al (6) dropped LPS into the nasal cavities of rats in order to establish animal models of rhinosinusitis and 4 days following administration, the sinus mucosa of rats were observed to be significantly thicker. This finding further confirmed that noninfectious inflammatory factors were involved in the occurrence and development of inflammatory diseases (10). Based on the known effects of LPS and the results of the aforementioned studies, the present study was conducted to explore the feasibility of establishing a mouse model of nasal polyps with sufficient quantities of LPS administered over a longer time frame. Furthermore, the present study aimed to analyze the histopathological features of immunologic tissues in the mouse model in order to further elucidate the roles and mechanisms of LPS in the formation of nasal polyps.

\section{Materials and methods}

Animals. A total of 30 female C57BL/6J mice (6-8 weeks old; weighing $1,823 \mathrm{~g}$ ) raised and maintained under specific pathogen free conditions were purchased from the Experimental Animal Center of Wuhan University (Wuhan, China). The mice were maintained under standard conventional conditions, consisting of a 12-h light/dark cycle, temperature of $18-22^{\circ} \mathrm{C}$ and humidity of $50-60 \%$. Food and water were available ad libitum. Mice were kept in the Renmin Hospital of Wuhan University. The present study protocol was approved by the Institutional Animal Care and Use Committee of Renmin Hospital of Wuhan University.

Experimental protocol. Mice were randomly divided into three groups of 10. For the normal control group (NS group), $20 \mu 1$ of sterile normal saline solution was dropped into the nasal cavities three times a week for 3 consecutive months. Mice in the low-(5 $\mu$ g LPS group) and high-dose (10 $\mu \mathrm{g}$ LPS group) model groups received 5 or $10 \mu \mathrm{g}$ of LPS (from Escherichia coli; Sigma-Aldrich, Merck Millipore, Darmstadt, Germany), respectively, in $20 \mu \mathrm{l}$ of sterile normal saline solutions with a 10- $\mu 1$ transferpettor three times a week for 3 consecutive months (Fig. 1).

Histopathological analysis. Nasal tissue samples were handled in accordance with previously described methods (7). However, the lung, liver and kidney were not decalcified. In order to facilitate direct observation of the distribution status of inflammatory cells of the sinuses, 5 mice in each group were randomly selected. Nasal lavage was not performed and the mice were anesthetized by intraperitoneal injection of $1 \%$ sodium pentobarbital $(50 \mathrm{mg} / \mathrm{kg})$, sacrificed with no pain and decapitated $24 \mathrm{~h}$ after the last nasal dropping. Tissue samples were fixed, decalcified and embedded in paraffin. Coronal sections with a thickness of $4 \mu \mathrm{m}$ were subsequently obtained. The nasal tissues were stained with hematoxylin-eosin to preliminarily assess the degree of inflammation and to observe if polyp formation was detected. The standards to determine the formation of nasal polyps in mice were in accordance with previously published standards, such as distinct mucosal bulges with neutrophilic infiltration and/or microcavity formation $(5,9)$. Periodic acid-Schiff staining was used to reveal hypertrophy and hyperplasia of goblet cells. Four continuous sections with similar sinus anatomy in each mouse were selected for observation at a magnification of $\mathrm{x} 400$ (highpower fields), using the BX51 upright microscope (Olympus Corporation, Tokyo, Japan). Image-Pro Plus version 6.0 software (Media Cybernetics, Inc., Rockville, MD, USA) was used to judge the area and density of the dyed region and the integrated optical density (IOD) value of the immunohistochemistry section. Goblet cells were indicated as the number of cells per mm length of the epithelial basement membrane $(\mathrm{N} / \mathrm{mm})$. Nasal polyps in a mouse were indicated as the total number of polyps in the nasal cavities of each mouse.

Toll-like receptor 4 (TLR4), cluster of differentiation (CD) 68 and myeloperoxidase (MPO) immunohistochemistry. Immunohistochemistry was performed in accordance with previously described methods (13). Paraffin sections were routinely dewaxed, rehydrated and incubated with $3 \% \mathrm{H}_{2} \mathrm{O}_{2}$ at room temperature for $10 \mathrm{~min}$ to inactivate endogenous peroxidase. The sections were placed into $0.01 \mathrm{M}$ citrate antigen retrieval solution, repaired by microwaving at $100^{\circ} \mathrm{C}$ for $10 \mathrm{~min}$ and cooled to room temperature prior to washing three times with phosphate-buffered saline (PBS) for 5 min each. Sections were subsequently blocked with $5 \%$ normal goat serum at room temperature for $30 \mathrm{~min}$ and incubated overnight at $4^{\circ} \mathrm{C}$ with anti-mouse TLR4 (cat. no. ab13556), CD68 (cat. no. ab125212) or MPO (cat. no. ab9535) polyclonal antibodies (Abcam, Cambridge, UK) at a dilution of 1:100. Following washing, the sections were incubated with horseradish peroxidase-labeled Streptavidin-Biotin Complex (1:200, cat. no. SA1029, Wuhan Boster Biotech Co., Ltd., Wuhan China) at $37^{\circ} \mathrm{C}$ in a humidified chamber for $30 \mathrm{~min}$ and subsequently washed three times with PBS for 5 min each. The sections were developed with diaminobenzidine and washed immediately with running water when brown particles appeared in the cytoplasm to terminate the reaction. The sections were secondarily stained with hematoxylin for $2 \mathrm{~min}$. The Image-Pro Plus version 6.0 software (Media Cybernetics, Inc.) was used to judge the area and density of the dyed region and the IOD value of the immunohistochemistry section, and immunohistochemical results were expressed as mean optical density.

Nasal lavage and ELISA. Nasal lavage was performed according to a previously described method with slight modification (13). Mice underwent partial tracheotomy under deep anesthesia by intraperitoneal injection of $1 \%$ sodium pentobarbital $(50 \mathrm{mg} / \mathrm{kg})$. A 22 -gauge catheter was inserted into the posterior naris from the opening of the trachea and along the direction of the nostrils. Sterile saline solution $(1 \mathrm{ml})$ 


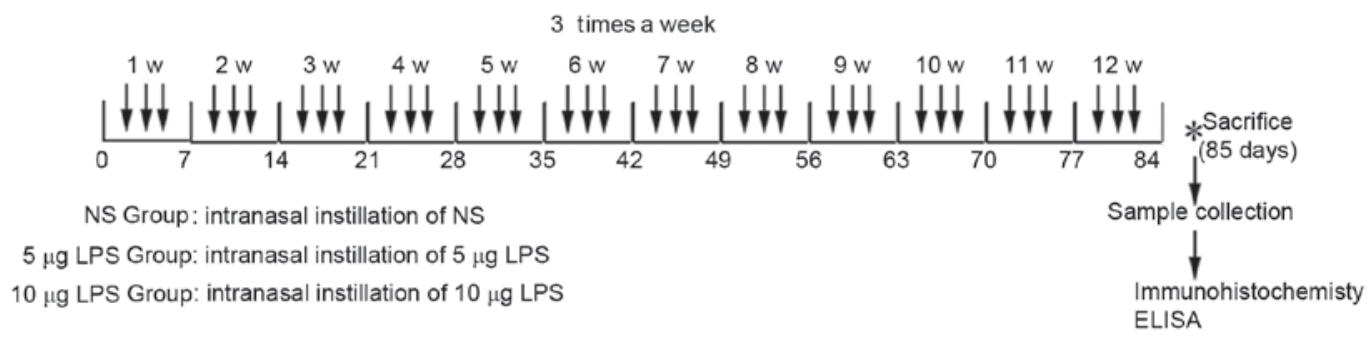

Figure 1. Protocol for the establishment of a mouse model of nasal polyps induced by LPS. A total of 5 or $10 \mu \mathrm{g}$ of LPS in $20 \mu 1$ of sterile normal saline solutions was administered into the nostrils of mice 3 times a week for 3 months. Samples were collected for immunohistochemistry and ELISA. LPS, lipopolysaccharides; NS group, control mice received normal saline solution; $5 \mu \mathrm{g}$ LPS group, mice received $5 \mu \mathrm{g}$ of LPS; $10 \mu \mathrm{g}$ LPS group, mice received $10 \mu \mathrm{g}$ of LPS.

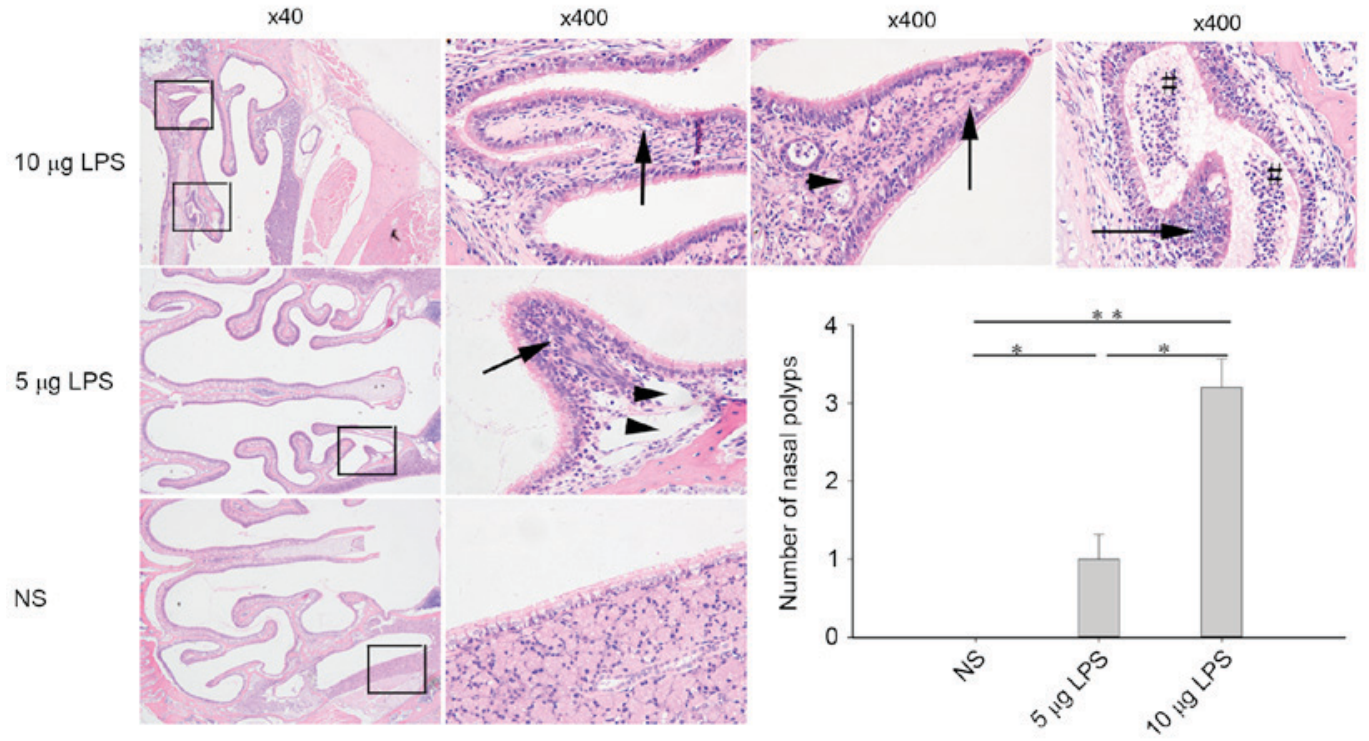

Figure 2. Nasal polyps were induced by continuous intranasal instillation of LPS. Nasal polyps are characterized morphologically by mucosal bulges (arrows) with a neutrophilic infiltration (\#) and microcavities (arrowheads). Nasal polyps were detected only in the mice treated with LPS for 3 months, and a significant difference was detected between the mice treated with 5 and $10 \mu \mathrm{g}$ of LPS. ${ }^{\mathrm{P}}<0.05 ;{ }^{* * *} \mathrm{P}<0.01$. Nasal polyps were stained with hematoxylin and eosin (magnification, $\mathrm{x} 40$ and $\mathrm{x} 400$ ). Data are presented as the mean \pm standard error of the mean. LPS, lipopolysaccharides; NS group, control mice received normal saline solution; $5 \mu \mathrm{g}$ LPS group, mice received $5 \mu \mathrm{g}$ of LPS; $10 \mu \mathrm{g}$ LPS group, mice received $10 \mu \mathrm{g}$ of LPS.

was perfused gently into the nasal cavities, lavage fluid was collected from the anterior naris, centrifuged at $220 \mathrm{x}$ g and $4^{\circ} \mathrm{C}$ for $10 \mathrm{~min}$, and the supernatant was stored at $-20^{\circ} \mathrm{C}$. Mice were sacrificed by dislocation with no pain under anesthesia following the nasal lavage. Cytokine expression levels in the supernatant were detected by ELISA. Interleukin (IL)-4 ELISA kits (cat. no. DY404) were purchased from R\&D Systems Inc., Minneapolis, MN, USA. Interferon (IFN)- $\gamma$ (cat. no. EK0375), tumor necrosis factor (TNF)- $\alpha$ (cat. no. EK0527) and IL-17 (cat. no. EK0431) ELISA kits were purchased from Wuhan Boster Biotech Co., Ltd. The detection sensitivities of all ELISA detection kits were $<2 \mathrm{pg} / \mathrm{ml}$. All operation methods were performed in strict accordance with the instructions provided in the kits.

Statistical analysis. All data are expressed as mean \pm standard error of the mean. The non-parametric Kruskal-Wallis test was used for comparing among the different groups. The Mann-Whitney U Test was used for pair-wise comparisons of any detected statistically significant differences. IBM SPSS Statistics 19.0 (IBM SPSS, Armonk, NY, USA) software was used for statistics analyses. $\mathrm{P}<0.05$ was considered to indicate a statistically significant difference.

\section{Results}

LPS induces nasal polyp formation in model mice. The sinus mucosa in the control mice was intact and evenly distributed. A small number of deciduous epithelial cells and infiltrative inflammatory cells were observed within the sinuses and no nasal polyp formation was indicated. Compared with the control group, model mice exhibited sinus mucosa that were not intact, which were accompanied by a large number of deciduous epithelial cells and infiltrative inflammatory cells within the sinuses. Furthermore, part of the mucosa proliferated to form obvious single or multiple polyps that protruded into the nasal cavities. These between-group differences were statistically significantly different and the number of polyps observed were significantly increased in the $5 \mu \mathrm{g}$ LPS group $(\mathrm{P}<0.05)$ and the $10 \mu \mathrm{g}$ LPS group $(\mathrm{P}<0.01)$ compared with the NS group. The nasal polyps were most obvious in the high-dose group and were located predominantly at the top of the nasal cavities and the lateral wall of the nasal cavities (Fig. 2).

LPS increases nasal mucus gland metaplasia in model mice. Mucus gland metaplasia is an important feature of nasal 


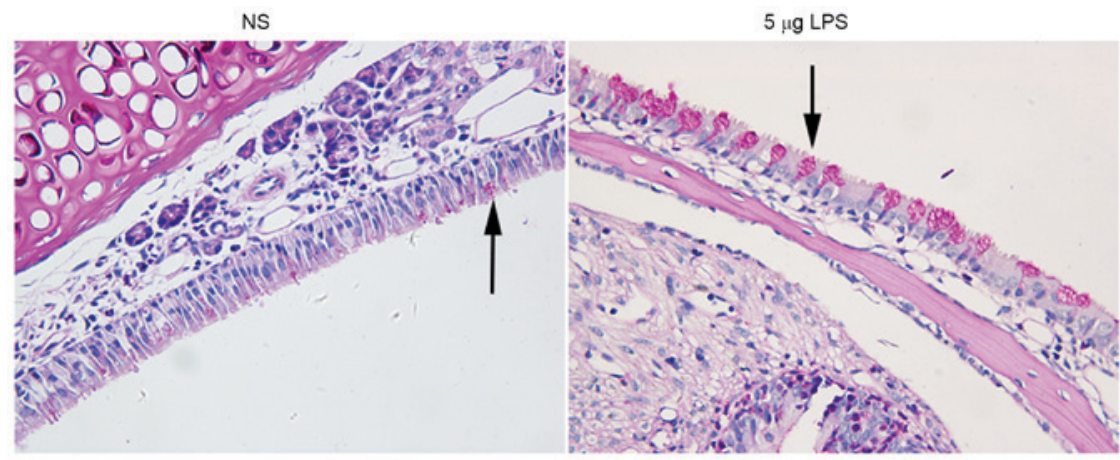

$10 \mu \mathrm{g}$ LPS
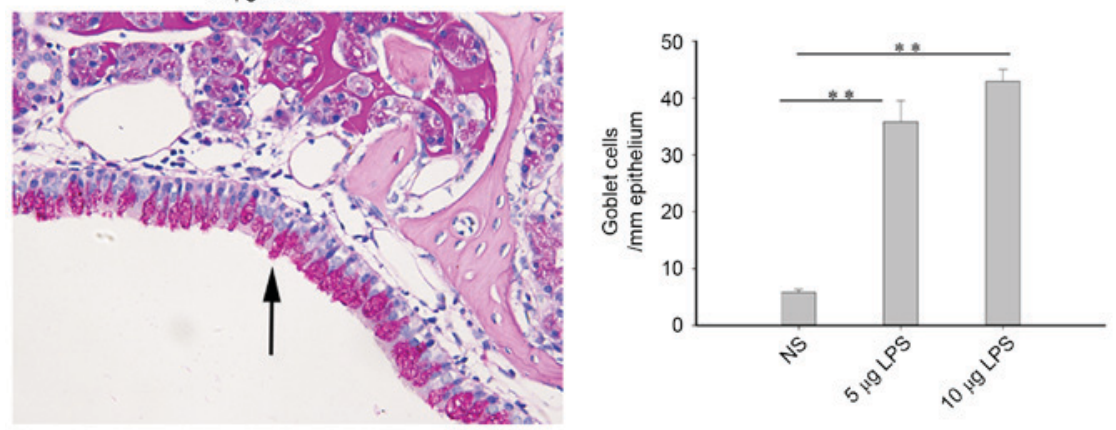

Figure 3. LPS increased the number of goblet cells in the epithelium with PAS staining (magnification, $\mathrm{x} 400$ ). The number of goblet cells in the epithelium of the LPS groups was more than in the epithelium of the NS group, and was further increased in the $10 \mu \mathrm{g}$ LPS group when compared with the $5 \mu \mathrm{g}$ LPS group. ${ }^{* * *} \mathrm{P}<0.01$. Data are presented as the mean \pm standard error of the mean. NS, normal saline; LPS, lipopolysaccharides; PAS, Periodic acid-Schiff; NS group, control mice received normal saline solution; $5 \mu \mathrm{g}$ LPS group, mice received $5 \mu \mathrm{g}$ of LPS; $10 \mu \mathrm{g}$ LPS group, mice received $10 \mu \mathrm{g}$ of LPS.

polyps. Goblet cells were rarely observed in the sinus mucosa of the control mice, such that only a small quantity of mucus glands were observed under the sinus mucosa. Compared with the control group, nasal goblet cells and mucus glands were significantly increased in the mouse model groups $(\mathrm{P}<0.01)$; however, no statistically significant differences were detected between the $5 \mu \mathrm{g}$ LPS group and $10 \mu \mathrm{g}$ LPS group (Fig. 3).

LPS increases expression of TLR4, CD68 and MPO in the nasal tissues of model mice. The principal detected inflammatory cells present in the nasal cavities and sinuses of mice were verified by immunohistochemistry. Few $\mathrm{CD}^{+} 8^{+}$and $\mathrm{MPO}^{+}$cells were indicated in the nasal cavities and sinuses of the control mice. Compared with the NS group, $\mathrm{CD}^{+} 8^{+}$and $\mathrm{MPO}^{+}$cells were significantly increased in the $5 \mu \mathrm{g}$ LPS group $(\mathrm{P}<0.01)$ and $10 \mu \mathrm{g}$ LPS group $(\mathrm{P}<0.01 ;$ Fig. 4). Furthermore, the present findings revealed a significantly higher number of $\mathrm{TLR}^{+}$cells were present in the nasal tissues of the $5 \mu \mathrm{g}$ LPS group $(\mathrm{P}<0.01)$ and $10 \mu \mathrm{g}$ LPS group $(\mathrm{P}<0.01)$ when compared with the NS group (Fig. 4). While the number of $\mathrm{MPO}^{+}$and TLR $4^{+}$cells present in the nasal tissue of mice in the $10 \mu \mathrm{g}$ LPS group were significantly increased when compared with the $5 \mu \mathrm{g}$ LPS group $(\mathrm{P}<0.05)$, no significant difference was observed in the number of $\mathrm{CD}^{+} 8^{+}$cells between these groups (Fig. 4).

Facilitating effects of LPS on the secretions of Th1 and Th17-related cytokines in the nasal lavage fluids of model mice. Inflammatory cytokines have an important role in the process of nasal polyp formation (1). The expression levels of inflammatory cytokines IFN- $\gamma, \mathrm{TNF}-\alpha$, IL-17 and IL-4 in the nasal cavities of mice in the control group were low.
Compared with the NS group, the IFN- $\gamma$, TNF- $\alpha$ and IL-17 protein levels exhibited in the nasal lavage fluids were significantly upregulated in the $5 \mu \mathrm{g}$ LPS group $(\mathrm{P}<0.01)$ and $10 \mu \mathrm{g}$ LPS group $(\mathrm{P}<0.05$; Fig. 5). IL-4 levels were significantly increased in the $5 \mu \mathrm{g}$ LPS group $(\mathrm{P}<0.05)$ when compared with the NS group; however, no significant difference in IL-4 levels was observed between the $10 \mu \mathrm{g}$ LPS group and the NS group (Fig. 5).

Safety of LPS used in nasal cavities of mice. To evaluate if LPS causes pathological damage to the vital organs of experimental animals, routine hematoxylin and eosin staining of the sections of the murine lung, liver and kidney of the mice in different groups was performed. No inflammation, necrosis or structural disorders in the lung, liver and kidney were observed in all groups, suggesting that LPS had no systematic toxic or side effects on the vital organs of the experimental animals (Fig. 6).

\section{Discussion}

Nasal polyps may be divided into two types, eosinophilic and neutrophilic. The eosinophilic nasal polyps are accompanied by significantly increased Th2 cells and M2 macrophages that may be established in animal models $(5,14)$. However, neutrophilic nasal polyps with more Th1 and Th17 cells are typically observed in those from Asian countries (1,3). To the best of our knowledge, this is the first time a successfully established mouse model of nasal polyps using LPS has been described. The neutrophils accounted for the majority of infiltrating inflammatory cells in the nasal polyps, accompanied by increased macrophages and enhanced expression 

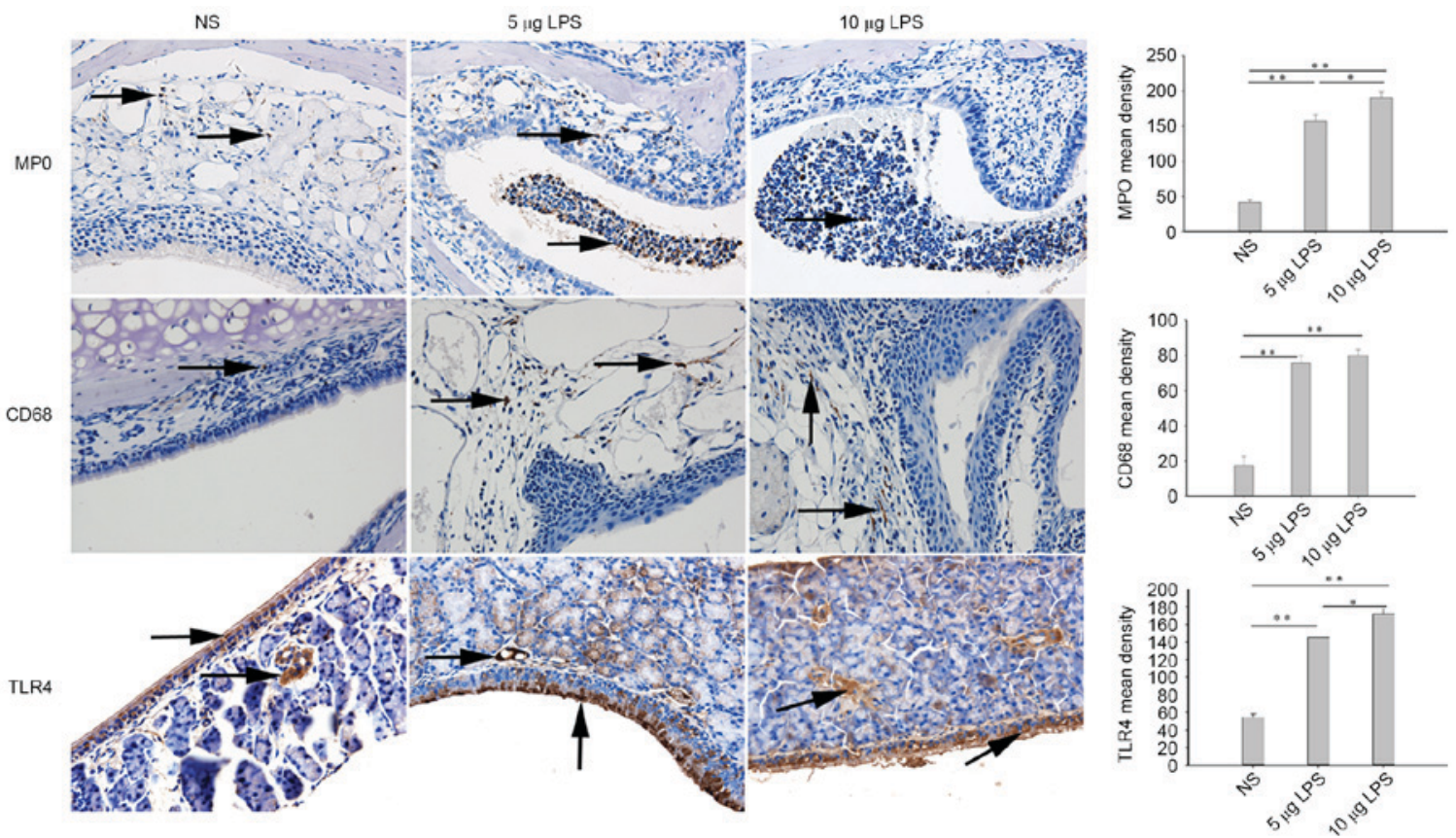

Figure 4. LPS increased MPO, CD68, and TLR4 expression levels in the nasal mucosa, as detected by immunohistochemistry using a Streptavidin-Biotin Complex (SABC) in the nasal mucosa of mice (magnification, $\mathrm{x} 400$ ). Yellow indicates MPO, CD68, and TLR4-positive cells. ${ }^{*} \mathrm{P}<0.05 ;{ }^{* *} \mathrm{P}<0.01$. Data are presented as the mean \pm standard error of the mean. LPS, lipopolysaccharides; MPO, myeloperoxidase; TLR4, Toll-like receptor NS, normal saline; NS group, control mice received normal saline solution; $5 \mu \mathrm{g}$ LPS group, mice received $5 \mu \mathrm{g}$ of LPS; $10 \mu \mathrm{g}$ LPS group, mice received $10 \mu \mathrm{g}$ of LPS.
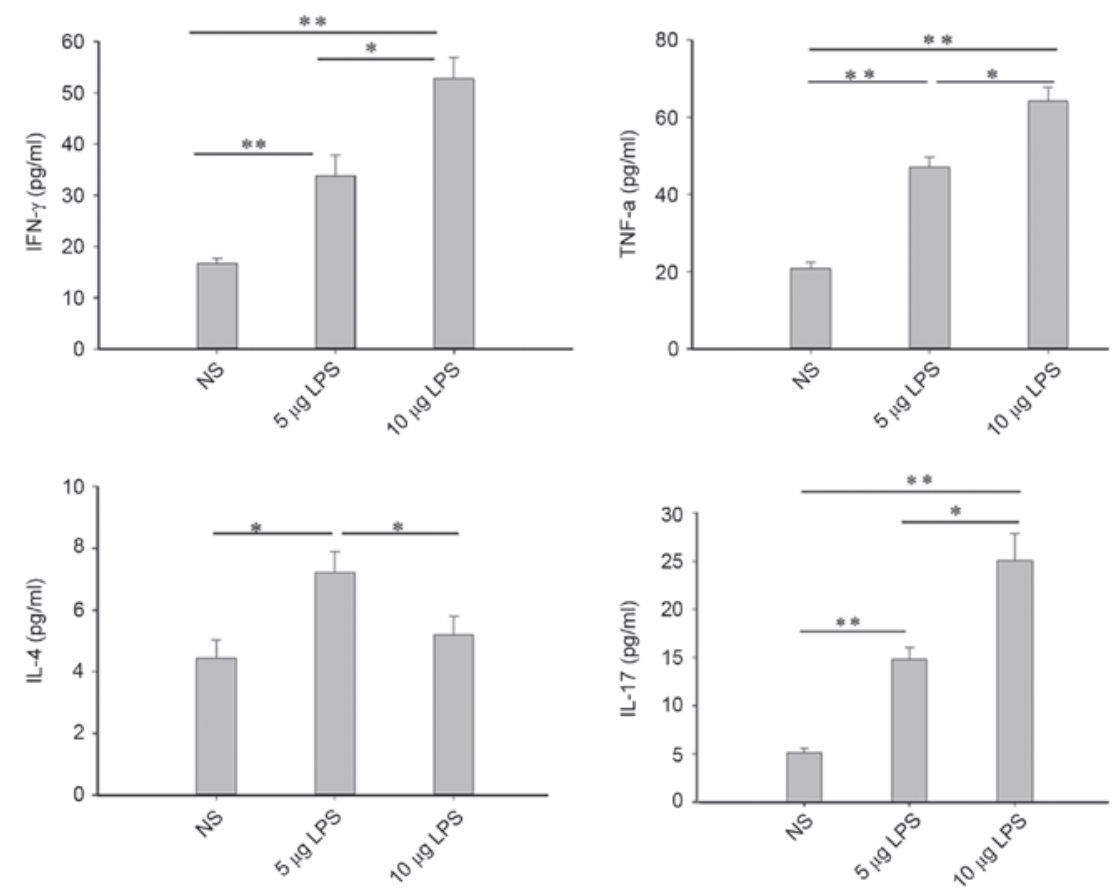

Figure 5. LPS increased IFN- $\gamma$, TNF- $\alpha$, IL-17 and IL-4 (only in the $5 \mu \mathrm{g}$ LPS group) levels in NLF. Cytokine levels in NLF were assessed by ELISA. "P $<0.05$; ${ }^{* *} \mathrm{P}<0.01$. Data are presented as the mean \pm standard error of the mean. LPS, lipopolysaccharides; IFN, interferon; IFN- $\gamma$, gamma interferon; TNF- $\alpha$, tumor necrosis factor- $\alpha$; IL, interleukin; NLF, nasal lavage fluid; NS, normal saline; NS group, control mice received normal saline solution; $5 \mu \mathrm{g}$ LPS group, mice received $5 \mu \mathrm{g}$ of LPS; $10 \mu \mathrm{g}$ LPS group, mice received $10 \mu \mathrm{g}$ of LPS.

of Th1- and Th17-related cytokines. Therefore, this model is consistent with the immune histopathologic features of major nasal polyps that may be typically exhibited in those of Asian descent $(1,3)$.

Nasal polyp formation results from a combination of individual susceptibility and environmental factors. Viruses, bacteria, fungi, allergens and alternative factors all have an important role in nasal tissue remodeling and the eventual formation of nasal polyps (2). Eosinophilic nasal polyps are primarily related to allergens $(1,14)$ and widely used endoscopic nasal surgery and long-term postoperative use of glucocorticoids have significantly increased the cure rate 


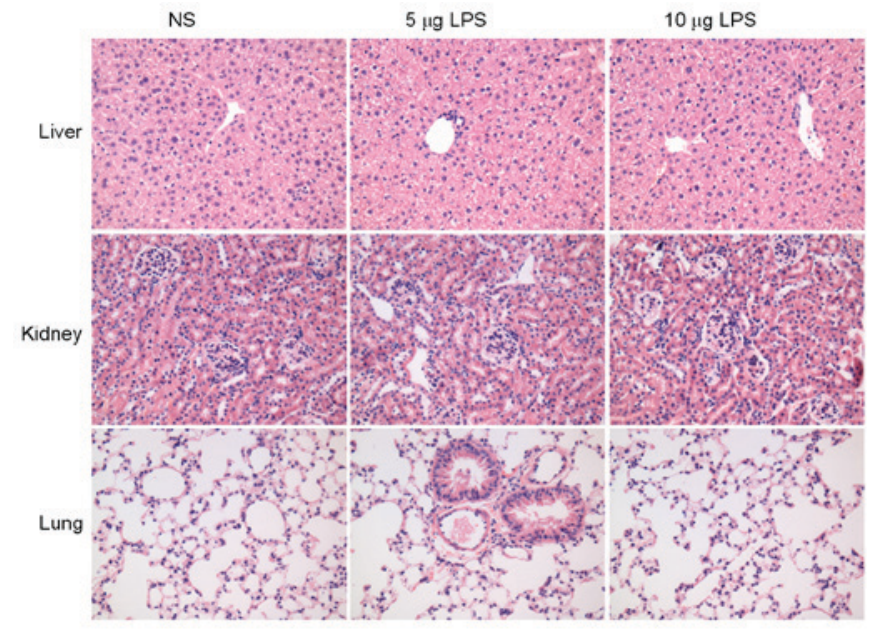

Figure 6. Hematoxylin and eosin staining of main organs of mice after NS or LPS treatment indicated no inflammation, necrosis or structural disorders in the lung, liver and kidney in all groups (magnification, x400). NS, normal saline; LPS, lipopolysaccharides; NS group, control mice received norma saline solution; $5 \mu \mathrm{g}$ LPS group, mice received $5 \mu \mathrm{g}$ of LPS; $10 \mu \mathrm{g}$ LPS group, mice received $10 \mu \mathrm{g}$ of LPS.

of eosinophilic nasal polyps (15). However, the pathogenesis of the neutrophilic nasal polyps is more complex and is typically combined with the concurrence of a variety of factors, which contribute to the difficulty in treating polyps (16). For this reason, it is considered important to establish animal models of neutrophilic nasal polyps. It is worth mentioning that bacterial infections associated with polyp formation are typically mixed infections (17) and the results of several studies have identified that the Gram-negative bacterial infections in rhinosinusitis were closely associated with drug resistance and postoperative recurrence $(11,12,18,19)$. Furthermore, it has been reported that following effective drug treatment, the LPS released by Gram-negative bacteria may persist for up to 3 months (6).

LPS is an abundant component that may be present in vivo or in vitro and particularly low doses of LPS may cause a bioactive effect, including poisoning of the body or provocation of an immune reaction (10). Long-term respiratory exposure to a sufficient concentration of LPS from the environment may result in sinusitis and pneumonia (10). LPS mediates biological effects through interactions with several different proteins, including LPS-binding protein (LBP), CD14 and TLR4. LBP initially binds directly to LPS and combines with CD14 to form a complex recognized and bound by TLR4 (20-23). Once internalized, LPS is able to activate several intracellular signaling pathways that include the IкB kinase-nuclear factor- $\kappa B$ pathway and three mitogen-activated protein kinase (MAPK) pathways, as well as initiate the production of a variety of inflammatory cytokines (20-22). LPS/TLR4 signaling pathways may be divided into MyD88-dependent and non-dependent pathways, the former mediating the release of pro-inflammatory cytokines, including IL-1 $\beta$, IL-6, IL-8 and TNF- $\alpha$. The latter pathway mediates the secretion of type I IFN $(22,23)$. The present study indicated that the expression levels of TLR4, TNF- $\alpha$ and IFN- $\gamma$ in the nasal mucosa were significantly upregulated following repeated intranasal LPS instillation, suggesting that both MyD88-dependent and non-dependent pathways may have been involved in biological effects of LPS. The present findings also revealed that IL-17 expression was significantly increased in the model groups when compared with the control group. Consistent with previous findings, LPS may regulate the secretion of IL-17 in a variety of cell types through TLR4 receptors (24-26). In addition, LPS may i) increase secretions of adhesion molecules, such as E-selectin in endothelial cells $(10,27)$; ii) induce the cellular proliferation, prostaglandin E2 production, and expression of cyclooxygenase- 2 and matrix metalloproteinase- 9 in peripheral blood mononuclear cells (20); iii) and promote the adhesion and migration of inflammatory cells into peripheral tissues. The expression of a variety of inflammatory cytokines may result in nasal tissue remodeling and the formation of nasal polyps, including goblet cell metaplasia, inflammatory cell infiltration, tissue fibrosis and tissue edema $(1,2)$. Nasal polyps may cause mechanical obstruction, including ventilation and drainage obstacles such as nasal congestion, runny nose, dizziness and olfactory dysfunction $(1,3)$.

The present results demonstrated that the expression of CD68 in nasal mucosa was increased following intranasal administration of 5 or $10 \mu \mathrm{g}$ of LPS in mice. However, it was not further distinguished whether the increased numbers of cells were M1 or M2 macrophages, although previous studies have indicated that LPS predominantly induces an increase in M1 macrophages $(28,29)$. Therefore, the increased $\mathrm{CD}^{+} 8^{+}$cells observed in the present study may be primarily M1 macrophages. Previous studies have suggested that very low doses of LPS significantly promoted ovalbumin-induced allergic inflammation, whereas larger doses of LPS inhibited ovalbumin-induced allergic inflammation $(30,31)$. In the present study, the levels of IL-4 protein present in nasal lavage liquids were measured and the results demonstrated that the expression levels of IL-4 in the nasal cavities were significantly increased following intranasal administration of $5 \mu \mathrm{g}$ of LPS; however, no statistically significant difference was observed in the $10 \mu \mathrm{g}$ LPS group compared with the NS group. This suggests that the current LPS dose of 5 or $10 \mu \mathrm{g}$ was large enough to induce inflammation consisting primarily of neutrophils, which was further administrated by increased $\mathrm{CD} 68^{+}$macrophages, $\mathrm{MPO}^{+}$cells, IFN- $\gamma$, TNF- $\alpha$ and IL-17, which is consistent with results from previous studies $(26,30,31)$. LPS commonly induces allergic reactions with the help of allergens, such as ovalbumin. Different doses of LPS may alter the type or extent of inflammation $(26,30,31)$. However, to the best of our knowledge, LPS alone has not been demonstrated to induce an allergic reaction. In the present study, LPS without allergens was used to establish a model of nasal polyps, and therefore the polyps were not attributable to allergens; however, allergens may induce the formation of the polyps in other cases. The results of the present study suggest that different doses of LPS lead to inconsistent types of inflammation, a result similar to those of previous studies $(26,30,31)$.

Kim et al (6) established a mouse model of rhinosinusitis with LPS and indicated marked thickening of the sinus mucosa without obvious polyp formation. These results may have been attributable to a modeling time that was too short as the study was completed in 3 days. The present study extended the modeling time to 3 months and successfully established a mouse model of neutrophilic nasal polyps. Based on an analysis of the morphological characteristics of 
the nasal polyps, it was revealed that the formation of nasal polyps in mice was primarily achieved by two approaches. One approach was through nasal tissue remodeling to form nasal polyps. Under the influence of inflammatory stimulation, secretion of the extracellular matrix increased and parts of the sinus mucosa became damaged and fell off into the sinus cavities. This prompted the sinus mucosa and inflammatory cells in the sinus cavities to form a tissue mass that was wrapped annularly by the proliferated basement membrane, causing hypoxia inside the tissue mass. Under the action of the multiple factors, such as hypoxia-inducible factors and inflammatory factors, angiogenesis was enhanced, the tissues were remodeled, and the structure of a typical nasal polyp formed. Another approach involved the proliferation and uplifting of local tissues. Affected by repeated inflammatory stimulation, the sinus mucosa became part of the substrate and local hyperplasia of the mucosa was formed into small upheavals, which subsequently turned into nasal polyps.

In the present study, LPS was used by the way of intranasal instillation, not by intravenous injection, which avoided systematic toxic or side effects resulting from the intravenous injection on the vital organs of the experimental animals. Since LPS is produced by various gram-negative bacteria and tends to form aggregates of varying sizes, various types of LPS, which may produce different inflammatory responses, require further investigation. In the present study, only LPS selected from $E$. coli was investigated as E. coli are common Gram-negative bacteria associated with nasal polyps (17). It is possible to obtain the same result after colonizing the nose with LPS-producing bacteria. Producing LPS is one of the important mechanisms of pathogenicity of Gram-negative pathogenic bacteria (10). Released LPS may be maintained for 3 months in local tissue to stimulate the releasing of inflammatory mediators, even in the instance that Gram-negative bacteria did not survive (6). However, no mouse of nasal polyps has been established by implanting Gram-negative bacteria into the nasal cavity, which requires further investigation.

Toll-like receptors (TLRs) include TLR1-9 subtypes. Various receptors are able to specifically bind to different ligands, such as TLR4 and LPS, TLR3 and viral ds-RNA, TLR2 and lipoproteins, and fat polypeptides and yeast polysaccharides, all of which may have roles in neutrophilic nasal polyps (32-34). However, it has not been reported whether administering TLR2 or TLR3 ligands may result in the formation of neutrophilic nasal polyps in an animal model. In the present study, TLR4 was chosen as the research subject based on the role of Gram-negative bacteria in the pathogenesis of chronic rhinosinusitis and nasal instillation of LPS in rats inducing significant inflammatory inflammation $(6,17)$. Nasal polyps were the result of tissue remodeling of the nasal mucosa during chronic inflammatory stimulation and would persist even if stimulation was not required. Nasal polyps did not automatically disappear without the treatment of drugs or surgery when they formed (2). Therefore, in the present study, the time was not extended for experiments when the animals developed significant nasal polyps after 90 days.

In conclusion, the current study established a mouse model of nasal polyps using LPS and provided a preliminary analysis of the characteristics of nasal polyps using histopathological methods. The predominant inflammatory cells identified in the nasal polyps were neutrophils, macrophages and higher levels of Th1- and Th17-related cytokines. Furthermore, the established model met with the histological features of nasal polyps that primarily consist of neutrophils, which are typically observed in Asian patients. The present study revealed that LPS may have a role in the process of nasal polyp formation through the TLR4 receptor pathway.

\section{Acknowledgements}

The present study was supported by the Hubei Province Health and Family Planning Scientific Research Project (grant no. WJ2015Z088) and the National Nature Science Foundation of China (grant no. 81372880 and 81300813).

\section{References}

1. Cao PP, Li HB, Wang BF, Wang SB, You XJ, Cui YH, Wang DY, Desrosiers $\mathrm{M}$ and Liu Z: Distinct immunopathologic characteristics of various types of chronic rhinosinusitis in adult Chinese. J Allergy Clin Immunol 124: 478-484, 484.e1-e2, 2009.

2. Fokkens WJ, Lund VJ, Mullol J, Bachert C, Alobid I, Baroody F, Cohen N, Cervin A, Douglas R, Gevaert P, et al: European position paper on rhinosinusitis and nasal polyps 2012. Rhinol Suppl 23: 3 p preceding table of contents, 1-298, 2012.

3. Wen W, Liu W, Zhang L, Bai J, Fan Y, Xia W, Luo Q, Zheng J, Wang $\mathrm{H}$, Li Z, et al: Increased neutrophilia in nasal polyps reduces the response to oral corticosteroid therapy. J Allergy Clin Immunol 129: 1522-1528.e5, 2012.

4. Smith KA and Rudmik L: Impact of continued medical therapy in patients with refractory chronic rhinosinusitis. Int Forum Allergy Rhinol 4: 34-38, 2014.

5. Kim DW, Khalmuratova R, Hur DG, Jeon SY, Kim SW, Shin HW, Lee CH and Rhee CS: Staphylococcus aureus enterotoxin $\mathrm{B}$ contributes to induction of nasal polypoid lesions in an allergic rhinosinusitis murine model. Am J Rhinol Allergy 25: e255-e261, 2011.

6. Kim DH, Jeon EJ, Park SN, Park KH, Park YS and Yeo SW: Effects of a tumor necrosis factor-a antagonist on experimentally induced rhinosinusitis. J Biomed Biotechnol 2011: 360457, 2011.

7. Wang H, Lu X, Cao PP, Chu Y, Long XB, Zhang XH, You XJ, Cui YH and Liu Z: Histological and immunological observations of bacterial and allergic chronic rhinosinusitis in the mouse. Am J Rhinol 22: 343-348, 2008 .

8. Jin M, Gu Z, Bian Z, Yang J, Cao Z, Yu X and Guo G: Developing a mouse model of acute bacterial rhinosinusitis. Eur Arch Otorhinolaryngol 268: 857-861, 2011.

9. Kim SW, Kim JH, Jung MH, Hur DG, Lee HK, Jeon SY and Kim DW: Periostin may play a protective role in the development of eosinophilic chronic rhinosinusitis with nasal polyps in a mouse model. Laryngoscope 123: 1075-1081, 2013.

10. Rylander R: Endotoxin in the environment-exposure and effects. J Endotoxin Res 8: 241-252, 2002.

11. Grindler D, Thomas C, Hall GS and Batra PS: The role of Stenotrophomonas maltophilia in refractory chronic rhinosinusitis. Am J Rhinol Allergy 24: 200-204, 2010.

12. Rombaux P, Collet S, Hamoir M, Eloy P, Bertrand B, Jamart F and Gigi J: The role of nasal cavity disinfection in the bacteriology of chronic sinusitis. Rhinology 43: 125-129, 2005.

13. Wang SB, Deng YQ, Ren J, Xiao BK, Liu Z and Tao ZZ: Exogenous interleukin-10 alleviates allergic inflammation but inhibits local interleukin-10 expression in a mouse allergic rhinitis model. BMC Immunol 15: 9, 2014.

14. Peterson S, Poposki JA, Nagarkar DR, Chustz RT, Peters AT, Suh LA, Carter R, Norton J, Harris KE, Grammer LC, et al: Increased expression of CC chemokine ligand 18 in patients with chronic rhinosinusitis with nasal polyps. J Allergy Clin Immunol 129: 119-127.e1-e9, 2012.

15. Potter PC and Pawankar R: Indications, efficacy, and safety of intranasal corticosteriods in rhinosinusitis. World Allergy Organ J 5 (Suppl 1): S14-S17, 2012. 
16. Mitroi M, Căpitănescu A, Georgescu CV, Mogoantă CA Popescu C, Georgescu M, Mitroi G and Ioniţă E: Expression pattern of CK7 and CK20 in nasal polyps, at patients with chronic rhinosinusitis with nasal polyposis. Rom J Morphol Embryol 52 (3 Suppl): S1051-S1057, 2011.

17. Dlugaszewska J, Leszczynska M, Lenkowski M, Tatarska A, Pastusiak T and Szyfter W: The pathophysiological role of bacterial biofilms in chronic sinusitis. Eur Arch Otorhinolaryngol 273: 1989-1994, 2016

18. Rom D, Snidvongs K, Sacks PL, Dalgorf D, Pratt E, Earls P, Sacks R and Harvey RJ: The impact of culturable bacterial community on histopathology in chronic rhinosinusitis. Int Forum Allergy Rhinol 4: 29-33, 2014.

19. Bhattacharyya $\mathrm{N}$ and Kepnes LJ: The microbiology of recurrent rhinosinusitis after endoscopic sinus surgery. Arch Otolaryngol Head Neck Surg 125: 1117-1120, 1999.

20. Curran CS, Demick KP and Mansfield JM: Lactoferrin activates macrophages via TLR4-dependent and -independent signaling pathways. Cell Immunol 242: 23-30, 2006.

21. Inubushi T, Kawazoe A, Miyauchi M, Kudo Y, Ao M, Ishikado A, Makino T and Takata T: Molecular mechanisms of the inhibitory effects of bovine lactoferrin on lipopolysaccharide-mediated osteoclastogenesis. J Biol Chem 287: 23527-23536, 2012.

22. Guha M and Mackman N: LPS induction of gene expression in human monocytes. Cell Signal 13: 85-94, 2001.

23. Tsukamoto $\mathrm{H}$, Fukudome $\mathrm{K}$, Takao S, Tsuneyoshi $\mathrm{N}$ and Kimoto M: Lipopolysaccharide-binding protein-mediated Toll-like receptor 4 dimerization enables rapid signal transduction against lipopolysaccharide stimulation on membrane-associated CD14-expressing cells. Int Immunol 22: 271-280, 2010.

24. Tanno D, Akahori Y, Toyama M, Sato K, Kudo D, Abe Y, Miyasaka $\mathrm{T}$, Yamamoto $\mathrm{H}$, Ishii $\mathrm{K}$, Kanno $\mathrm{E}$, et al: Involvement of Gr-1 dull+ cells in the production of TNF- $\alpha$ and IL-17 and exacerbated systemic inflammatory response caused by lipopolysaccharide. Inflammation 37: 186-195, 2014.

25. Cao AT, Yao S, Stefka AT, Liu Z, Qin H, Liu H, Evans-Marin HL, Elson CO, Nagler CR and Cong Y: TLR4 regulates IFN- $\gamma$ and IL-17 production by both thymic and induced Foxp3+ Tregs during intestinal inflammation. J Leukoc Biol 96: 895-905, 2014
26. Barboza R, Câmara NO, Gomes E, Sá-Nunes A, Florsheim E, Mirotti L, Labrada A, Alcântara-Neves NM and Russo M: Endotoxin exposure during sensitization to blomia tropicalis allergens shifts TH2 immunity towards a TH17-mediated airway neutrophilic inflammation: Role of TLR4 and TLR2. PLOS One 8: e67115, 2013

27. Elass-Rochard E, Legrand D, Salmon V, Roseanu A, Trif M, Tobias PS, Mazurier J and Spik G: Lactoferrin inhibits the endotoxin interaction with CD14 by competition with the lipopolysaccharide-binding protein. Infect Immun 66: 486-491, 1998.

28. Qin H, Holdbrooks AT, Liu Y, Reynolds SL, Yanagisawa LL and Benveniste EN: SOCS3 deficiency promotes M1 macrophage polarization and inflammation. J Immunol 189: 3439-3448, 2012.

29. Al Faraj A, Sultana Shaik A, Pureza MA, Alnafea M and Halwani R: Preferential macrophage recruitment and polarization in LPS-induced animal model for COPD: Noninvasive tracking using MRI. PLoS One 9: e90829, 2014.

30. Dong L, Li H, Wang S and Li Y: Different doses of lipopolysaccharides regulate the lung inflammation of asthmatic mice via TLR4 pathway in alveolar macrophages. J Asthma 46: 229-233, 2009.

31. Kim YK, Oh SY, Jeon SG, Park HW, Lee SY, Chun EY, Bang B, Lee HS, Oh MH, Kim YS, et al: Airway exposure levels of lipopolysaccharide determine type 1 versus type 2 experimental asthma. J Immunol 178: 5375-5382, 2007.

32. Lee S, Hwang HJ and Kim Y: Modeling the role of TGF- $\beta$ in regulation of the Th17 phenotype in the LPS-driven immune system. Bull Math Biol 76: 1045-1080, 2014.

33. Zhang Q, Wang CS, Han DM, Sy C, Huang Q, Sun Y, Fan EZ, Li Y and Zhou B: Differential expression of Toll-like receptor pathway genes in chronic rhinosinusitis with or without nasal polyps. Acta Otolaryngol 133: 165-173, 2013.

34. Tengroth L, Millrud CR, Kvarnhammar AM, Kumlien Georén S, Latif L and Cardell LO: Functional effects of Toll-like receptor (TLR)3, 7, 9, RIG-I and MDA-5 stimulation in nasal epithelial cells. PLoS One 9: e98239, 2014. 